\title{
Effectiveness of Ultrasonic and Manual Dynamic Agitation Techniques in Irrigant Penetration: An in vitro Study
}

\author{
${ }^{1}$ Manasi Khare, ${ }^{2}$ Baranya S Suprabha, ${ }^{3}$ Amit Yadav, ${ }^{4}$ Ramya Shenoy, ${ }^{5}$ Karen Boaz, ${ }^{6}$ Arathi Rao
}

\section{ABSTRACT}

Aim: The aim is to compare the extent of irrigant penetration into root canals up to the working length and in simulated lateral canals after passive ultrasonic irrigation (PUI) and manual dynamic agitation (MDA).

Materials and methods: Root canals of 36 single-rooted extracted teeth were shaped using rotary files. Irrigation was done with $5.25 \%$ sodium hypochlorite and $17 \%$ ethylenediaminetetraaceticacid. Teeth were decalcified in 5\% nitric acid. Lateral canals were created by inserting $10 \mathrm{~K}$-files and then, the teeth were cleared using methyl salicylate. Samples were randomly divided into three groups of 12 teeth each: Group I - Control, group II - PUI, and group III - MDA. A contrast solution was delivered to the root canals during final irrigation and activation. Specimens were photographed using dental operating microscope, and the mean length of dye penetration was measured.

Results: Data were analyzed using analysis of variance (ANOVA), Tukey test, and repeated measures ANOVA. Passive ultrasonic irrigation group showed the highest penetration of the irrigant upto the working length followed by MDA. Manual dynamic agitation and PUI groups had equivocal results in lateral canal irrigation.

Conclusion: Passive ultrasonic irrigation technique is the most effective in delivering the irrigants up to the working length. The effectiveness of PUI and MDA is equivocal in lateral canal irrigation, and hence, MDA can be considered an alternative to PUI, in the case of nonavailability of PUI.

Clinical significance: The clinician can consider the use of MDA technique for irrigant agitation in root canals as an alternative to PUI, based on the extent of irrigant penetration.

Keywords: Laboratory research, Lateral canals, Manual agitation, Root canal irrigants, Ultrasonics.

\footnotetext{
${ }^{1,2,6}$ Department of Paedodontics and Preventive Dentistry Manipal College of Dental Sciences, Manipal University Manipal, Karnataka, India

${ }^{3}$ Department of Conservative Dentistry and Endodontics Manipal College of Dental Sciences, Manipal University, Manipal Karnataka, India

${ }^{4}$ Department of Public Health Dentistry, Manipal College of Dental Sciences, Manipal University, Manipal, Karnataka, India

${ }^{5}$ Department of Oral Pathology, Manipal College of Dental Sciences, Manipal University, Manipal, Karnataka, India

Corresponding Author: Baranya S Suprabha, Department of Paedodontics and Preventive Dentistry, Manipal College of Dental Sciences, Manipal University, Manipal, Karnataka, India Phone: +910824-2428716, e-mail: suprabha.bhat@manipal.edu
}

How to cite this article: Khare M, Suprabha BS, Yadav A, Shenoy R, Boaz K, Rao A. Effectiveness of Ultrasonic and Manual Dynamic Agitation Techniques in Irrigant Penetration: An in vitro Study. World J Dent 2017;8(3):207-212.

\section{Source of support: Nil}

Conflict of interest: None

\section{INTRODUCTION}

Removal of all vital and necrotic pulp tissue, microorganisms, and their toxins, along with the smear layer is a necessity for successful root canal treatment. However, irregularities within the canal, such as the lateral canals, make it difficult to completely shape and clean the root canal system. ${ }^{1,2}$ For this reason, instrumentation is combined with adequate irrigation to flush the debris out and disinfect the canals. ${ }^{3}$ The irrigation system should deliver the irrigant to the entire root canal system, including areas untouched by mechanical instrumentation, such as lateral canals. ${ }^{4}$

Root canal irrigation delivery and agitation systems can be divided into two broad categories, manual agitation techniques, and machine-assisted agitation devices. ${ }^{1}$ Manual irrigation includes positive pressure irrigation, which is commonly performed with a syringe and a side-vented needle. ${ }^{5}$ These needles are close ended with a lumen $2 \mathrm{~mm}$ from their end on lateral surface, creating turbulence around the end of the needle, directed toward the apex with a divergence of approximately $30^{\circ} .6$

Manual dynamic agitation (MDA) has been described as a simple and cost-effective technique for activation of the irrigant. It involves repeated insertion of a well-fitting gutta-percha cone to the working length of a previously shaped canal. ${ }^{1}$ On the contrary, there are machineassisted irrigation techniques, such as sonic, ultrasonic, and apical negative pressure irrigation. ${ }^{7}$ The term passive ultrasonic irrigation (PUI) refers to the activation of irrigant by an ultrasonically activated file or tip, which is not used for canal preparation. ${ }^{8}$

Previous studies have shown that activation of irrigants may allow better penetration of irrigants in lateral canals and apical third of the canal when compared with positive pressure irrigation alone. ${ }^{1,7,9}$ However, none of the reported studies compare ultrasonic activation and MDA in this regard. Hence, this study was carried out to evaluate the extent of penetration of irrigants in simulated 
lateral canals and up to the working length after ultrasonic activation and MDA.

The null hypothesis tested was that there is no difference in the extent of irrigant penetration between positive pressure irrigation without activation, ultrasonic activation, and MDA.

\section{MATERIALS AND METHODS}

Thirty-six single-rooted teeth extracted for periodontal or orthodontic reasons were selected. The study was approved by the Institutional Ethics Committee before the commencement. Teeth were kept for 2 hours in $4 \%$ sodium hypochlorite $(\mathrm{NaOCl})$ and any visible calculus was removed ultrasonically. The presence of a single root canal was verified radiographically by taking three films at different angulations. Root length was standardized to $15 \mathrm{~mm}$ by decoronating the samples and patency of the root canals was obtained using a 10 K-file (Dentsply Maillefer, Ballaigues, Switzerland). Root canal shaping was performed to a working length of $14 \mathrm{~mm}$ using Protaper Universal Rotary files (Dentsply Maillefer, Ballaigues, Switzerland) up to F2. During instrumentation, $1.5 \mathrm{~mL}$ of 5.25\% $\mathrm{NaOCl}$ (Vishal Dentocare, India) was delivered between each instrumentation. Finally, the canals in all groups were irrigated with $3 \mathrm{~mL} 5.25 \% \mathrm{NaOCl}$ followed by $3 \mathrm{~mL} \mathrm{17 \%}$ ethylenediamine tetraacetic acid (EDTA) (Vishal Dentocare, India) and $3 \mathrm{~mL} \mathrm{5.25 \%} \mathrm{NaOCl.} \mathrm{All}$ irrigation was done using 31-gauge double-side vent needle (Vishal Dentocare, India), placed $2 \mathrm{~mm}$ short of working length during irrigation. The rate of irrigation was $3 \mathrm{~mL}$ per minute. Overall, the samples received $12 \mathrm{~mL}$ of $\mathrm{NaOCl}$ and $3 \mathrm{~mL}$ of EDTA.

Teeth were cleared using the technique described by Venturi et al. ${ }^{10}$ The teeth were submerged in $5 \%$ nitric acid for 36 hours, and the solution was renewed every 8 hours. Once decalcified, samples were cleared with tap water for 3 minutes, and lateral canals were created inserting $10 \mathrm{~K}$-file at 2, 4.5, and $6 \mathrm{~mm}$ short of the working length on the buccal and lingual walls, perpendicular to the external surface. ${ }^{9,11}$ A total of 210 simulated lateral canals were created, six in each tooth, with two lateral canals at each of the three levels. Samples were then dehydrated using ascending grades of alcohol: $60 \%$ ethanol for 8 hours, $80 \%$ ethanol for 4 hours, and $96.6 \%$ ethanol for 2 hours. Samples were then submerged and stored in 99.9\% methyl salicylate for clearing and re-hardening of dental tissues as well as preserving the transparency.

To simulate the clinical scenario, a closed system was created by coating each root with soft modeling wax. A coronal reservoir for the irrigant was also created with modeling wax. A 25 size gutta-percha point was inserted into the root canal up to the working length during this procedure, to prevent blockage of the canals. Samples were then randomly assigned to three experimental groups $(\mathrm{n}=12)$ using a random number table:

- Group I: Positive pressure irrigation (conventional)

- Group II: PUI

- Group III: MDA

A contrast solution containing $90 \%$ of $5.25 \% \mathrm{NaOCl}$ and $10 \%$ ink marker (BD Diagnostic Systems, New Jersey, USA) was prepared and delivered to the prepared root canals using the following protocol.

In group I, the contrast solution was delivered using 31-gauge double-side vent needle. The needle was placed $2 \mathrm{~mm}$ short of the working length with a constant rate of 3 $\mathrm{mL}$ per minute. No activation of the irrigant was done. In group II, after delivery of contrast solution as in group I, ultrasonic activation was performed with a stainless steel ultrasonic file ISO No. 10 mounted on an ultrasonic unit (Satellac, Acteon Group Dental, Mérignac, France). The file was inserted $2 \mathrm{~mm}$ short of the working length and passively activated without any filing motion using a power setting of 3 . This procedure was performed in three cycles of 20 seconds each for a total activation time of 1 minute. ${ }^{9}$ In group III, after irrigation with contrast solution as in group I, short 2 to $3 \mathrm{~mm}$ push-pull strokes were given for 1 minute using a Protaper F2 size (0.06 taper) gutta-percha cone followed by 1 minute soaking in the contrast solution, then $17 \%$ EDTA for 1 minute with short push-pull strokes using the same gutta-percha cone followed by 1 minute soaking and a third cycle with contrast solution for 1 minute with short push-pull strokes. The size of gutta-percha cone was decided so as to limit the penetration of gutta-percha till the working length. All push-pull strokes were performed manually at an approximate rate of 100 strokes per minute. ${ }^{12}$ The methodology is summarized in Flow Chart 1.

All root canal shaping procedures and irrigation protocols were performed by a single trained operator. After final irrigation protocol, the specimens were photographed using operating microscope (Seiler IQ, Missouri, USA) at $11 \times$ magnification and $25 \mathrm{~cm}$ focal length (Fig. 1). The orientation of all samples in relation to the recording microscope was standardized in all groups. The digitized images were analyzed using the ImageJ software (National Institutes of Health, Bethesda, USA) for greater accuracy and calculation of absolute values, by single-calibrated examiner who was blinded to the irrigation protocol. Calibration was done using 10 samples, which were not included in the study. During calibration, intraexaminer reliability and interexaminer reliability were calculated using intraclass correlation coefficient. They were found to be more than 0.9 for all the measurements $(0.99$ and 0.97 respectively, at $2 \mathrm{~mm}$, 0.92 and 0.91 respectively, at $4.5 \mathrm{~mm}$ level lateral canal, 


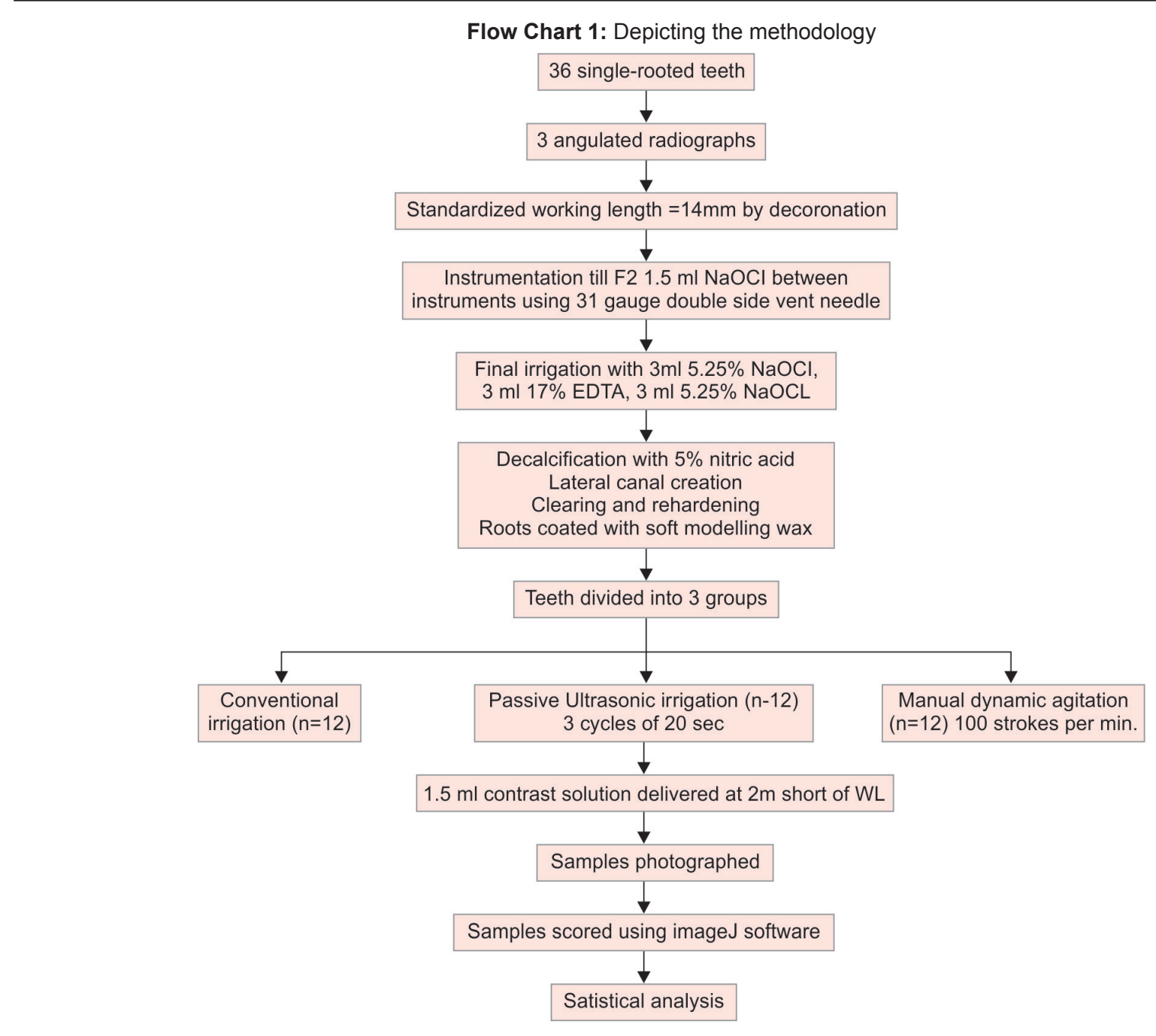

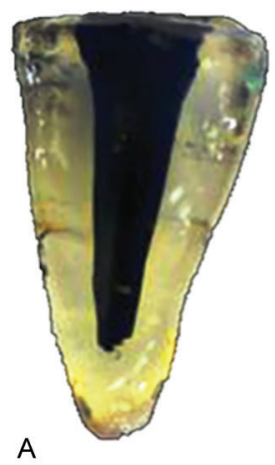
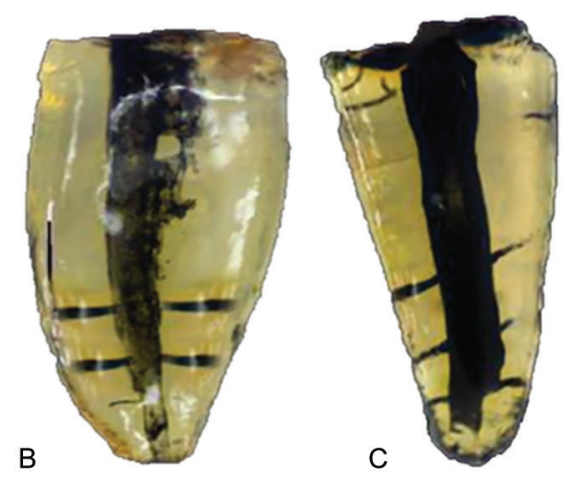

Figs $1 \mathrm{~A}$ to $\mathrm{C}:$ Representative sample of specimen in each group: (A) Conventional irrigation (Group I); (B) passive ultrasonic irrigation (Group II); (C) MDA (Group III)

0.99 and 0.90 respectively, at $6 \mathrm{~mm}$ level lateral canal and 1 and 0.99 respectively, for the working length).

Images were placed on a grid and the scale of measurement $(1 \mathrm{~cm}=10$ grid squares $)$ was set using the grid. The extent of apical penetration in the main canal was measured (in millimeters) from the point $1 \mathrm{~mm}$ short of the anatomic apex (corresponding to the working length) to the most apical level of dye penetration. The total lengths of simulated lateral canals were measured.
The extent of penetration of the contrast solution into the simulated lateral canals at all the levels $(2,4.5$, and $6 \mathrm{~mm}$ from the working length) was measured as the length between the endpoints of dye penetration in millimeters.

\section{Statistical Analysis}

All statistical analysis was performed using Statistical Package for the Social Sciences version 16 for Windows release software (SPSS Inc., Chicago, Illinois, USA). Mean and standard deviation were calculated, and the extent of apical penetration up to the working length was compared using analysis of variance (ANOVA). Multiple comparisons were carried out using post hoc Tukey test. The extent of dye penetration in lateral canals was analyzed using repeated measures ANOVA. The level of significance was set at 0.05 .

\section{RESULTS}

Group II (PUI) showed the highest mean apical penetration up to the working length followed by group III (MDA) and group I (positive pressure irrigation), as the distance between the most apical level of dye penetration to the 
Table 1: Mean extent of apical dye penetration in the lateral canals

\begin{tabular}{|c|c|c|c|c|c|}
\hline \multirow[b]{3}{*}{ Type of irrigation } & \multirow[b]{3}{*}{$N$} & \multirow[b]{2}{*}{ Distance from apex } & \multicolumn{3}{|c|}{ Lateral canal dye penetration } \\
\hline & & & $2 \mathrm{~mm}$ & $4 \mathrm{~mm}$ & $6 \mathrm{~mm}$ \\
\hline & & Mean $\pm S D(\mathrm{~mm})$ & Mean $\pm S D(\mathrm{~mm})$ & Mean $\pm S D(m m)$ & Mean $\pm S D(\mathrm{~mm})$ \\
\hline Conventional & 12 & $2.94 \pm 0.48$ & $0.69 \pm 0.28$ & $1.31 \pm 0.12$ & $1.63 \pm 0.20$ \\
\hline PUI & 12 & $0.50 \pm 0.48$ & $1.22 \pm 0.72$ & $1.67 \pm 0.09$ & $1.94 \pm 0.08$ \\
\hline MDA & 12 & $1.38 \pm 0.46$ & $1.10 \pm 0.11$ & $1.52 \pm 0.10$ & $1.87 \pm 0.09$ \\
\hline$F$ & & 81.79 & 29.23 & 22.35 & 19.09 \\
\hline$p$-value & & $<0.001$ & $<0.001$ & $<0.001$ & $<0.001$ \\
\hline
\end{tabular}

SD: Standard deviation

Table 2: Intergroup comparison of the extent of apical dye penetration up to the working length (post hoc Tukey test)

\begin{tabular}{lllcc}
\hline & & \multicolumn{3}{c}{ Subset for alpha $=0.05$} \\
\cline { 3 - 5 } Group & $N$ & 1 & 2 & 3 \\
\hline Ultrasonic & 12 & 0.50 & 1.37 & \\
MDA & 12 & & & 2.93 \\
Conventional & 12 & & & \\
p-value & & $<0.001$ & $<0.001$ & $<0.001$ \\
\hline
\end{tabular}

level $1 \mathrm{~mm}$ short of apex (up to the level of working length) was least for group II. A statistically significant difference between the mean apical dye penetration values of the groups was seen (Table 1). Post hoc test showed that the mean apical dye penetration value of group II was significantly higher than both groups I and III. There was also statistically significant difference between group I and III values (Table 2).

Chi-square test revealed no statistical difference in the mean lateral canal lengths between the groups $(p=0.925$, 0.085 , and 0.545 at 2,4 , and $6.5 \mathrm{~mm}$ respectively). Group II also had the highest mean dye penetration into lateral canals followed by groups III and I, at all levels and the difference was statistically significant (Table 1 ). The mean dye penetration values of groups II and III were both significantly higher than group I. There was no statistical difference in mean dye penetration values between groups II and III (Table 3 ).

\section{DISCUSSION}

Lateral canals and the apical end of the root canal have very narrow diameter which creates surface tension barrier for adequate flow of irrigant. As accessory canal position and status is difficult to determine in a clinical setting, a standardized model simulating accessory canals and capable of yielding repeatable results was used in this study. ${ }^{5,7,9}$

The EDTA was used in the MDA group during agitation of the irrigant, as repeated rubbing of gutta-percha cone against the wall can result in the formation of smear layer. ${ }^{12}$ On the contrary, removal of smear layer occurs when PUI is used with $\mathrm{NaOCl} .^{13}$ Thus, both irrigation
Table 3: Intergroup comparison of the extent of dye penetration in the lateral canals at various working lengths (repeated measures ANOVA)

\begin{tabular}{llll}
\hline & & \multicolumn{2}{c}{ Subset for alpha $=0.05$} \\
\cline { 3 - 4 } Group & $N$ & 1 & 2 \\
\hline Conventional & 12 & 1.21 & \\
PUI & 12 & & 1.49 \\
MDA & 12 & & 1.58 \\
p-value & & $<0.001$ & 0.09 \\
\hline
\end{tabular}

protocols in MDA and PUI group could result in similar effects on the smear layer.

The results of this study revealed that there was a significant difference among the groups for irrigant penetration into the apical third of the root canal and into the simulated lateral canals. Hence, the null hypothesis was rejected. Our results are in accordance with the previous studies which concluded that irrigation activation techniques increase irrigation efficiency up to the working length ${ }^{7,9,14}$ and to ensure irrigant flow in noninstrumented areas, such as lateral canals. ${ }^{4,7,9}$

In group I, a double-side vent needle was used, and the irrigating needle was placed $2 \mathrm{~mm}$ short of the working length. At this level, irrigant reaches the working length with minimum apical extrusion. ${ }^{15}$ However, irrigant replacement is limited to 1 to $1.5 \mathrm{~mm}$ apical to the needle tip due to an apical vapor lock which adversely affects debridement efficacy of conventional irrigation. This results in fluid stagnation at the most apical end of the canal, in the absence of strong turbulent flow of the irrigant. ${ }^{16}$

Both the activation techniques were useful in circumventing the apical vapor lock. Previous studies comparing PUI with syringe irrigation concluded that PUI is more effective in removing remnants of pulp tissue and dentin debris. ${ }^{17,18}$ Ultrasonic activation of the irrigant also resulted in maximal lateral canal penetration because the irrigant was activated with sufficient force to overcome the apical vapor lock. ${ }^{4}$ Furthermore, the file oscillation has the potential to create acoustic streaming and cavitation effects. ${ }^{19}$ In addition, ultrasonics has the advantage of synergistic effect on the "tissue-dissolving" capability of $\mathrm{NaOCl}$ due to increased wetting of pulp tissue remnants following agitation. ${ }^{20}$ 
Manual dynamic agitation technique may be useful in circumventing apical gas entrapment at 0 to $2 \mathrm{~mm}$ of the apical seat by repeated gutta-percha insertions. ${ }^{12}$ However, the apical penetration of the irrigant in MDA group was inferior to PUI group. This could be because the frequency of push-pull motion of the gutta-percha point at 100 strokes per minute generates currents at a lower frequency $(3.3 \mathrm{~Hz})^{14}$ as compared with higher frequency of 40 to $45 \mathrm{kHz}$ generated due to secondary acoustic streaming during PUI. ${ }^{9}$ This resulted in more effective breaking of the vapor lock leading to more apical irrigant flow in the PUI group.

The push-pull motion of the gutta-percha point in the canal causes physical stretching, folding, and cutting of fluid laminas resulting in higher intracanal pressure leading to equivalent results as the PUI group, in lateral canal irrigation. It also allows better mixing of fresh unreacted solution with the spent reacted molecules of the active $\mathrm{NaOCl}$ irrigant. Manual dynamic irrigation has been shown to be significantly more effective than auto dynamic and conventional irrigation in an earlier study. ${ }^{14}$ It is also simple and less expensive, but has the disadvantage of being more laborious and time consuming. ${ }^{1}$

The results of this study prove that MDA is equally effective as PUI in lateral canal irrigation. However, the results need to be confirmed with in vivo studies. Further studies are also needed to compare the ability of these two agitation techniques to remove bacteria and debris in the root canal.

\section{CONCLUSION}

Passive ultrasonic irrigation technique is the most effective in delivering the irrigants up to the working length followed by MDA and conventional irrigation. The effectiveness of PUI and MDA is equivocal in lateral canal irrigation, and hence, MDA can be considered as an alternative to PUI, in the case of nonavailability of PUI.

\section{CLINICAL SIGNIFICANCE}

Irrigant activation/agitation should be done to increase the penetration of the irrigants up to the working length as well as into lateral canals. The results of the article suggest that the clinician can consider the use of MDA technique for irrigant agitation in root canals as an alternative to PUI, based on the extent of irrigant penetration and considering the cost factor.

\section{REFERENCES}

1. Gu LS, Kim JR, Ling J, Choi KK, Pashley DH, Tay FR. Review of contemporary irrigant agitation techniques and devices. J Endod 2009 Jun;35(6):791-804.
2. Burleson A, Nusstein J, Reader A, Beck M. The in vivo evaluation of hand/rotary/ultrasound instrumentation in necrotic, human mandibular molars. J Endod 2007 Jul;33(7): 782-787.

3. Bystrom A, Sundqvist G. The antibacterial action of sodium hypochlorite and EDTA in 60 cases of endodontic therapy. Int Endod J 1985 Jan;18(1):35-40.

4. Castelo-Baz P, Martín-Biedma B, Cantatore G, Ruíz-Piñón M, Bahillo J, Rivas-Mundiña B, Varela-Patiño P. In vitro comparison of passive and continuous ultrasonic irrigation in simulated lateral canals of extracted teeth. J Endod 2012 May;38(5):688-691.

5. De Gregorio C, Paranjpe A, Garcia A, Navarrete N, Estevez R, Esplugues EO, Cohenca N. Efficacy of irrigation systems on penetration of sodium hypochlorite to working length and to simulated uninstrumented areas in oval shaped root canals. Int Endod J 2012 May;45(5):475-481.

6. Boutsioukis C, Verhaagen B, Versluis M, Kastrinakis E, Wesselink PR, van der Sluis LW. Evaluation of irrigant flow in the root canal using different needle types by an unsteady computational fluid dynamics model. J Endod 2010 May;36(5):875-879.

7. De Gregorio C, Estevez R, Cisneros R, Paranjpe A, Cohenca N. Efficacy of different irrigation and activation systems on the penetration of sodium hypochlorite into simulated lateral canals and up to working length: an in vitro study. J Endod 2010 Jul;36(7):1216-1221.

8. Al-Jadaa A, Paqué F, Attin T, Zehnder M. Acoustic hypochlorite activation in simulated curved canals. J Endod 2009 Oct;35(10):1408-1411.

9. De Gregorio C, Estevez R, Cisneros R, Heilborn C, Cohenca N. Effect of EDTA, sonic, and ultrasonic activation on the penetration of sodium hypochlorite into simulated lateral canals: an in vitro study. J Endod 2009 Jun;35(6): 891-895.

10. Venturi M, Di Lenarda R, Prati C, Breschi L. An in vitro model to investigate filling of lateral canals. J Endod 2005 Dec;31(12):877-881.

11. Anna-Júnior A, Tanomaru-Filho M, Duarte MA, da Silva G, Bosso R, Guerreiro-Tanomaru J. Filling of simulated lateral canals with gutta percha or resilon when using thermomechanical compaction. J Cons Dent 2014;17(3):212-215.

12. Susin L, Liu Y, Yoon JC, Parente JM, Loushine RJ, Ricucci D, Bryan T, Weller RN, Pashley DH, Tay FR. Canal and isthmus debridement efficacies of two irrigant agitation techniques in a closed system. Int Endod J 2010 Dec;43(12):1077-1090.

13. Cameron JA. The synergistic relationship between ultrasound and sodium hypochlorite: a scanning electron microscope evaluation J Endod 1987 Nov;13(11):541-545.

14. McGill S, Gulabivala K, Mordan N, Ng YL. The efficacy of dynamic irrigation using a commercially available system (RinsEndo) determined by removal of a collagen "biomolecular film" from an ex vivo model. Int Endod J 2008 Jul;41(7):602-608.

15. Boutsioukis C, Lambrianidis T, Verhaagen B, Versluis M, Kastrinakis E, Wesselink PR, van der Sluis LW. The effect of needle-insertion depth on the irrigant flow in the root canal: Evaluation using an unsteady computational fluid dynamics model. J Endod 2010 Oct;36(10):1664-1668.

16. Tay FR, Gu LS, Schoeffel GJ, Wimmer C, Susin L, Zhang K, Arun SN, Kim J, Looney SW, Pashley DH. Effect of vapor 
lock on root canal debridement by using a side-vented needle for positive-pressure irrigant delivery. J Endod 2010 Apr;36(4):745-750.

17. Gutarts R, Nusstein J, Reader A, Beck M. In vivo debridement efficacy of ultrasonic irrigation following hand-rotary instrumentation in human mandibular molars. J Endod 2005 Mar;31(3):166-170.

18. Passarinho-Neto JG, Marchesan MA, Ferreira RB, Silva RG, Silva-Sousa YT, Sousa-Neto MD. In vitro evaluation of endodontic debris removal as obtained by rotary instrumentation coupled with ultrasonic irrigation. Aust Endod J 2006 Dec;32(3):123-128.

19. Van der Sluis LW, Versluis M, Wu MK, Wesselink PR. Passive ultrasonic irrigation of the root canal: a review of the literature. Int Endod J 2007 Jun;40(6):415-426.

20. Cheung GS, Stock CJ. In vitro cleaning ability of root canal irrigants with and without endosonics. Int Endod J 1993 Nov;26(6):334-343. 